\title{
SCADidoC
}

Infer, Interpret \& Inspire Science

International Journal of Dentistry and Oral Science (IJDOS)

ISSN: $2377-8075$

\section{Comparison Of Salivary Calcium Levels In Children With And Without ECC}

Research Article

Dhanalakshmi MDS ${ }^{1}$, Pradeepa Ramani MDS², Mahesh Ramakrishnan MDS ${ }^{3 *}$.

${ }^{1}$ PhD Scholar, Department of Pedodontics \& Preventive DentistrySaveetha Dental College and Hospital, Saveetha Institute of Medical and Technical Science, Saveetha University, Chennai 600077, Tamilnadu, India.

${ }^{2}$ Professor, Department of Oral \& Maxillo facial pathology, Saveetha Dental College and Hospital, Saveetha Institute Of Medical and Technical Science, Saveetha University, Chennai 600077, Tamilnadu, India.

${ }^{3}$ PhD Scholar, Department of Pedodontics \& Preventive Dentistry, Saveetha Dental College and Hospital, Saveetha Institute Of Medical and Technical Science, Saveetha University, Chennai 600077, Tamilnadu, India.

Abstract

Background: Early Childhood Caries (ECC) is a chronic disease of childhood affecting the primary dentition. It is also termed as nursing caries or baby bottle tooth decay. It has a multifactorial etiology and saliva and its components is one of the important etiological factors of ECC. Salivary calcium protects the tooth from demineralization and maintains oral homeostasis. The present study was done to compare the salivary calcium levels in children with and without ECC.

Materials And Methods: It is a cross-sectional observational study conducted at Saveetha Dental College and Hospitals. Children between 37 to 72 months were examined and 15 caries free and 15 children with ECC were recruited for the study. The examination and sample collection were done by a single qualified Pediatric dentist. The samples were collected and analysed for calcium levels by colorimetric method.

Results: The results showed that there was a statistically significant difference in salivary calcium level in children with and without ECC. In children with Early Childhood Caries the mean calcium concentration in samples of unstimulated saliva was $\mathrm{z} 4.96 \pm 1.64$

The mean calcium concentration caries free children were found to be $9.14 \pm 3.5$

Conclusion: Salivary calcium concentration was high in Caries free group and found to be low in children with ECC. The present study emphasize that the salivary calcium definitely influences the development of carious lesion.

Keywords: Early Childhood Caries (Ecc); Saliva; Salivary Calcium.

\section{Introduction}

Oral cavity is a distinctive ecosystem, which harbours wide range of microorganism. Dental caries is the chronic disease and considered as a serious public health problemin many developing countries.[1,2] Dental caries affecting primary dentition is called as Early childhood caries (ECC) and defined as the presence of one or more decayed (non-cavitated or cavitated), missing (due to caries), or filled tooth surfaces in any primary tooth in a child 72 months of age or younger. [3] AAPD also states that, in children less than 3 years of age, any sign of smooth-surface caries is an indicative of severe ECC (ECC-S). From 3 to 5 years of age, 1 or more cavitated smooth surfaces, lost (because of caries), or clogged in the anterior maxillary temporary teeth index $\geq 4$ (at 3 years of age), $\geq 5$ (at 4 years of age), or $\geq 6$ (at 5 years of age) corresponds to ECC-S. [4] The concepts of ECC and Early Severe Childhood Caries (S-ECC) have been used for over ten years to describe the state of caries present in children under 6 years. The most common reason for ECC is improper bottle feeding and hence ECC is also been termed as bottle caries," "nursing caries," "baby bottle tooth decay," or "night bottle mouth." ECC develops as a white-spot lesion in the upper primary incisors along the gingival margin and later progresses to complete destruction of the crown [5,6] The maxillary incisors are commonly affected and the mandibular incisors are least affected due to the protection of tongue and saliva from salivary glands. [7]

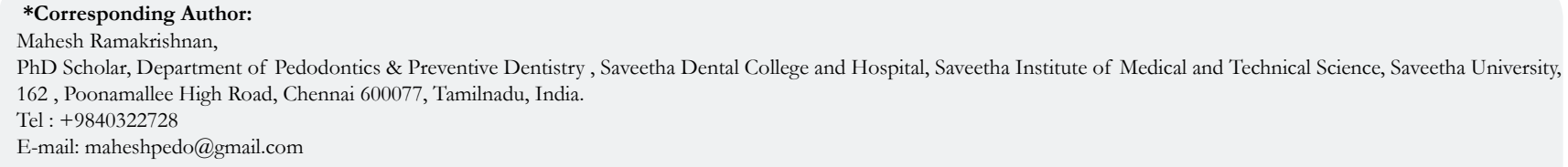

Copyright: Mahesh Ramakrishnan MDS $^{\circ}$ 2021. This is an open-access article distributed under the terms of the Creative Commons Attribution License, which permits unrestricted use, distribution and reproduction in any medium, provided the original author and source are credited. 
The main causative agent of ECC is Mutans Streptococci namely Streptococcus mutans and streptococcus sobrinus. Streptococcus Mutans and Streptococcus Sobrinus initiate the carious lesion whereas, lactobacilli plays and important role in progression of carious lesion. [8] Apart from microbial factors, diet also plays an imperative role in ECC. Prolonged intake of sugary substances, fermentable carbohydrates is the main source of ECC. School going children are more vulnerable for the development of ECC due to the change in dietary habits. $[9,10]$ Though, these factors play an important role in initiation of caries, but cannot be considered as a sole factor to develop a carious lesion in all cases. Hence there are several other contributing factors like salivary factors also play a major role in development of caries.

Saliva is the mixed glandular secretion which is constantly exposed to the teeth and the oral mucosa. The three major salivary glands are the parotid, submandibular and sublingual. The saliva also contains secretions from minor salivary glands. Saliva plays an immense role in the prevention of dental caries and protection of oral mucosa. Saliva can be classified as unstimulated or stimulated. The unstimulated saliva consists of a mixture of secretion from major and minor salivary glands. Its continuous presence in oral cavity throughout the day helps to protect the teeth and oral mucosa and hyposalivation leads to development of carious lesion. Hence, it reflects the importance of saliva in development of dental caries. [11,12] The salivary flow and its composition play an important role on the development of dental caries. It is important to consider the role of saliva in demineralization and remineralization process of tooth exposed to the oral cavity

Salivary calcium and phosphateplay an imperative role in oral homeostasis. Calcium is a bivalent ion excreted along with salivary proteins into the lumen of the acinus. Hence, the concentration of salivary calcium is dependent on the salivary flow rate. The ionized calcium fraction is about $50 \%$, and it is strongly dependent on the salivary $\mathrm{pH}$. Saliva consists of various inorganic compounds like calcium and phosphate, which helps in rehardening softened, demineralized enamel. Demineralization occurs at a low $\mathrm{pH}$ when there is a disproportionate in the mineral content between the oral environment and in the tooth. During these series of event, the enamel crystal is dissolved by the acids produced by the micro-organisms and leads to loss of calcium in the saliva leading to demineralization of tooth. Low level of salivary calcium and phosphate levels affects the equilibrium between demineralization and remineralization process and ultimately leads to caries development. Hence it explains the importance of salivary calcium in maintaining and preserving the tooth integrity from demineralization. These inorganic ions also influence the driving force for the precipitation of calcium hydroxyapatite (HAP), the principal inorganic component of dental hard tissues. [13] It also helps in post-eruptive maturation of enamel and increase resistance to demineralization. The concentration of salivary calcium in a healthy individual is $5.8 \mathrm{mg} / \mathrm{dl}(2.2-11.3 \mathrm{mg} / \mathrm{dl})$ in resting saliva and $6 \mathrm{mg} / \mathrm{dl}$ in stimulated saliva as reported by Jenkins. [11] Parotid saliva contains more phosphate and less $\mathrm{Ca}+2$ ions compared to mixed saliva. On contrast, the level of $\mathrm{Ca}+2, \mathrm{Mg}+2$, and $\mathrm{Zn}+3$ in mixed saliva are significantly higher than the parotid saliva.

Few studies carried out pertaining to the mechanism of how mineral concentration of saliva influence plaque during sugar chal- lenge. The studies reported that, during sugar intake, inorganic phosphorus concentrations in saliva may fall with increases in flow rate, while the $\mathrm{Ph}$ of the saliva drops and it becomes desaturated with respect to calcium phosphates. Simultaneously, mineral concentrations in the fluid phase of plaque may rise and allow calcium and/or phosphate to diffuse out. High concentrations of these constituents in stimulated saliva may reduce outward diffusion, whilst low concentrations may encourage movement of ions out of plaque. $[14,15]$

Several conflicting reports have been published on the salivary calcium level and its role in ECC. Aruna S et al reported an increase in salivary calcium level in caries-free children compared to children with ECC.[16] On contrary, Turtola et al and Elizarova and Petrovich reported an increase in salivary calcium in children with increased caries activity. $[17,18]$ Due to the existence of contradictory results, the present study was done to study thepossible relationship of salivary calcium level and ECC.

\section{Aims And Objectives}

1.To estimate the levels of calciumin the salivary samples of children between 3-6 years of age.

2.To compare the salivary calcium levels in children with and without ECC.

\section{Hypothesis}

There are significant differences in salivary calcium levels in children with and without ECC.

\section{Main Aim}

Establish whether there are significant differences in the salivary calcium level in children with and without ECC.

\section{Materials And Methods}

\section{Type Of Study}

The present study is a cross-sectional case control study. Children between 3-6 years of age, who reported to the Department of Pediatric and Preventive Dentistry, Saveetha Dental College, were included in the study.

\section{Ethical Approval}

This study "Comparison of Salivary calcium levels in children with and without ECC" has been approved by the Ethics Committee of the Saveetha Dental College and Hospitals.

The study was carried out following the principles of the Declaration of Helsinki. We invited children to be a part of the study after informing the parents/care givers about the clinical measurements and surveys to be applied, and their potential risks and benefits. The agreement was registered through an informed consent endorsed by the Ethics Committee of the Saveetha Dental College and Hospitals. 15 children with ECC were selected based on dmft index and 15 caries free children were recruited to participate in the study 


\section{Inclusion Criteria}

Children of both genders, between 3-6 years of age.

Parents who agree to take part in the study, by signing an informed consent

\section{Exclusion Criteria}

Uncooperative children who do not allow the examination and/ or collection of saliva.

Children with systemic diseases and/or pharmacological treatment.

\section{Clinical Examination}

Examination for dental caries was carried out by a single qualified Pediatric Dentist using mouth mirror and dental explorer. The decayed, missing, and filled teeth (dmft) scores for primary teeth were recorded using WHO criteria 18and the data's was entered by an assistant on data collection forms. Teeth extracted for trauma reasons were not included in $\mathrm{dmft}$ score. Restored teeth with recurrent caries and teeth filled with temporary materials were considered as decayed. The dmft value should be more than 1 for caries active children and 0 for caries free children.

Those children who fulfilled the inclusion criteria were screened for dental caries and categorized into 2 groups depending on their caries status

1. Group I: Caries free group

2. Group II: Children with ECC

\section{Collection of Salivary Samples}

The children were instructed not to eat or drink anything 1 hour before the sample collection to prevent contamination. [19-21] The children were asked to rinse their mouth to remove any food debris present. The salivary samples were collected between 10.00 am -11.00 am to avoid circadian variation. Unstimulated saliva was collected in sterile tube. Saliva was collected based on the technique explained by Wu et al. [22] The child was allowed to sit in well-ventilated and well-lit atmosphere. The children were asked to keep their head at $45^{\circ} \mathrm{C}$, with one hand holding the sterile tube. The saliva was allowed to drip into the tube and allowed till sufficient for analysis without measuring the froth the quantity. The samples were transferred immediately to the laboratory. The samples were stored at $-20^{\circ} \mathrm{C}$ until analysis.

\section{Laboratory Procedures}

Analysis of the samples was done on the same day. Samples were centrifuged at $5000 \mathrm{rpm}$ for 5 minutes to remove bacteria and other debris. [23] Each sample was then estimated for calcium concentrations. The measurement of salivary calcium was done by colorimetric method. In colorimetric method, calcium and methyl-thymol blue makes a colour that is proportional with the calcium ion in solution. [24] These values were tabulated and subjected to statistical analysis.

\section{Statistical Analysis}

All data was analysed by using the SPSS 20.0 software. Descriptive statistics that included mean, standard deviation and minimum and maximum values were determined for 2 groups. A p value of 0.05 or less was considered for standard significance.

\section{Results}

The mean scores and standard deviations for salivary calcium are depicted in Table 1. In Group I (caries free) the mean concentrations of calcium was found to be $9.14 \mathrm{mg} / \mathrm{dl}$ and in Group II (Caries - active), the mean concentrations of calcium were4.96 $\mathrm{mg} / \mathrm{dl}$ respectively.

\section{Discussion}

ECC is a chronic disease of childhood and remains as a major health problem in many developed countries. Several etiological factors were attributed to the development of ECC and the low salivary calcium levels remains as one of the etiological factors in development of ECC. Salivary calcium plays an important role from the beginning of eruption of primary teeth to permanent teeth through diffusion of calcium ions in the tooth enamel and increases the resistance of the tooth. It influences the precipitation of hydroxyapatite crystals of enamel and hence it acts as an important factor in post eruptive maturation. [11,13,26,27]Thus, the deficiency of salivary calcium could be an additional cause for development of ECC. Studies state that the critical $\mathrm{Ph}$ is lower for children and demineralizationoccurs at a low $\mathrm{pH}$. [19] As a result of this, there will be undersaturation of mineral ions of saliva as compared to tooth's mineral content. During these series of events, the carbonated apatite crystals of enamel get dissolved by organic acids and results in loss of ca ions in tooth enamel. If any

Table 1: Comparison of Salivary calcium levels in Caries Free children and in children with ECC

\begin{tabular}{|l|l|l|l|l|l|}
\hline $\begin{array}{l}\text { Salivary } \\
\text { Calcium }\end{array}$ & \multicolumn{2}{|l|}{$\begin{array}{l}\text { Caries Free Group I } \\
(\mathrm{N}=15)\end{array}$} & \multicolumn{2}{l|}{ Group II (n=15) } & \multirow{2}{*}{ P Value } \\
\cline { 2 - 5 } & Mean & SD & Mean & SD & \\
\hline & 9.14 & 3.5 & 4.96 & 1.64 & $<0.001^{*}$ \\
\hline
\end{tabular}

$p>0.05$ Not significant

$\mathrm{p}<0.001$ highly significant

SD - Standard deviation 
timely action taken by usage of remineralizing agent, the ca ions of the enamel get restored.

Saliva consists of supersaturated calcium and helps in remineralization, whereas undersaturated saliva leads to development of incipient lesion. Similarly, the quantity of salivary calcium varies between different salivary glands. For instance, parotid saliva has less calcium content than submandibular and sublingual salivary glands. Few studies carried out pertaining to the mechanism of how mineral concentration of saliva influence plaque during sugar challenge. The studies reported that, during sugar intake, inorganic phosphorus concentrations in saliva may fall with increases in flow rate, while the $\mathrm{Ph}$ of the saliva drops and it becomes desaturated with respect to calcium phosphates. Simultaneously, mineral concentrations in the fluid phase of plaque may rise and allow calcium and/or phosphate to diffuse out. High concentrations of these constituents in stimulated saliva may reduce outward diffusion, whilst low concentrations may encourage movement of ions out of plaque. $[14,15,27,28]$ In the present study, the mean level of salivary calcium is increased in caries-free children when compared to caries-active children and is found to be statistically significant. (Table 1) This high concentration of salivary calcium levels could be a reason for remineralization of incipient lesion in caries free children. The saliva that is super saturated with calcium acts as a reservoir and enhances remineralization and overrides demineralization.

Several conflicting reports have been published on the salivary calcium and phosphate level and its role in ECC. A study done by Aruna $\mathrm{S}$ et al reported an increase in salivary calcium level in caries-freechildren compared to children with ECC. [16] On contrary, Turtola et al and Elizarova and Petrovich reported an increase in salivary calcium in children with increased caries activity. $[17,18]$ On the other hand, few studies insisted that there was no difference in salivary calcium in caries-free and caries-active children. [29][32] A study done by Kargul et al found no significant differences in salivary calcium concentrations between caries- free and caries active children children. [33]

Shaw Let al evaluated calcium levels in saliva and plaque and found that the calcium level in saliva and plaque to be significantly higher in caries-free than a high caries group. [34] Similarly, Kittner D et al reported an increase in salivary calcium levels in persons with a low caries experience. [35]In regards to caries activity and calcium levels, Ashley found that the salivary calcium increased with decreasing caries activity, whereas Karshan observed that salivary calcium concentration decreased with increasing caries activity. $[36,37]$ Preeti et al and Aryeh et al investigated salivary calcium level and found that the salivary concentration of calcium tends to be lower in children as compared to adults. This clearly explains that the salivary calcium balance is lower in children; hence it suggests that a deficient in calcium levels make them more susceptible to development of caries. [19,38]

An invitro study done by Amaechi B et al had found that, a chewing gum comprised of calcium and phosphorus would supersaturate the saliva with these ions and inhibit demineralization. 36 Hence with the usage of this chewing gum, there will be a stimulation of saliva and thereby the levels of inorganic ions would increase and possibly inhibit demineralization[40].

The limitation of the study includes, smaller sample size. Hence in future, studies are needed with a greater number of children from the same socioeconomic stratum, to have a more representative and homogeneous sample.

\section{Conclusion}

Salivary calcium concentration was high in Caries free group and found to be low in children with ECC. The present study emphasize that the salivary calcium definitely influences the development of carious lesion. However, clinical interpretation of the results obtained in the present study should be made carefully as it involved only one of the host factor components of the multifactorial etiology of dental caries.

This article is of importance to paediatric dentist as:

-As ECC is considered as a major oral health problem among children, this paper evaluated the role of calcium and its protective function

-The salivary calcium can be considered as a useful parameter to measure caries experience in children along with other host factors.

\section{References}

[1]. Seow WK. Biological mechanisms of early childhood caries. Community Dent Oral Epidemiol. 1998;26(1 Suppl):8-27. Pubmed PMID: 9671196.

[2]. Tsai AI, Chen CY, Li LA, Hsiang CL, Hsu KH. Risk indicators for early childhood caries in Taiwan. Community Dent Oral Epidemiol. 2006 Dec;34(6):437-45. Pubmed PMID: 17092272.

[3]. Council O, American Academy of Pediatric Dentistry. Policy on early childhood caries (ECC): unique challenges and treatment options. Pediatr Dent. 2003;25(2):114-8.

[4]. Kawashita Y, Kitamura M, Saito T. Early childhood caries. International journal of dentistry. 2011 Oct 10;2011.

[5]. Kagihara LE, Niederhauser VP, Stark M. Assessment, management, and prevention of early childhood caries. J Am Acad Nurse Pract. 2009 Jan;21(1):110. Pubmed PMID: 19125889.

[6]. J. R. Pinkham, Pediatric Dentistry: Infancy through Adolescence, Saunders, London, UK, 3rd edition, 1999.

[7]. O. Fejerskov and Kidd E. A. M., Dental Caries: The Disease and Its Clinical Management, Blackwell Munksgaard, Oxford, UK, 2nd edition, 2008.

[8]. van Houte J. Role of micro-organisms in caries etiology. J Dent Res. 1994 Mar;73(3):672-81. Pubmed PMID: 8163737.

[9]. Marshall TA, Levy SM, Broffitt B, Warren JJ, Eichenberger-Gilmore JM, Burns TL, et al. Dental caries and beverage consumption in young children. Pediatrics. 2003 Sep;112(3 Pt 1):e184-91. Pubmed PMID: 12949310.

[10]. Bowen WH, Lawrence RA. Comparison of the cariogenicity of cola, honey, cow milk, human milk, and sucrose. Pediatrics. 2005 Oct;116(4):921-6. Pubmed PMID: 16199702.

[11]. Jenkins NG, Lichter P, Muir J, Richardson OJ and Feldman B: ThePhysiology and Biochemistry of the mouth. 4th Ed.,1978; 284-358.

[12]. Boyce WT, Den Besten PK, Stamperdahl J, Zhan L, Jiang Y, Adler NE, et al. Social inequalities in childhood dental caries: the convergent roles of stress, bacteria and disadvantage. Soc Sci Med. 2010 Nov;71(9):1644-52. Pubmed PMID: 20870333.

[13]. Anderson P, Hector MP, Rampersad MA. Critical pH in resting and stimulated whole saliva in groups of children and adults. Int J Paediatr Dent. 2001 Jul;11(4):266-73. Pubmed PMID: 11570442.

[14]. DAWES C, JENKINS GN. Some inorganic constituents of dental plaque and their relationship to early calculus formation and caries. Arch Oral Biol. 1962 Mar-Apr;7:161-72. Pubmed PMID: 13884022.

[15]. Rankine CA, Prihoda TJ, Etzel KR, Labadie D. Plaque fluid pH, calcium and phosphorus responses to calcium food additives in a chewable candy. Arch Oral Biol. 1989;34(10):821-4. Pubmed PMID: 2610616.

[16]. 1Aruna S, Meenakshi B, Rama KV, Valarmathi S. Salivary levels of calcium and phosphorus in children with and without early childhood caries: A pilot study. SRM Journal of Research in Dental Sciences. 2020 Apr 1;11(2):72.

[17]. Turtola L. Dental caries and its prevention. Pro Finn Den Soc 1978; 74:367. 
[18]. World Health Organization. Basic Methods. Geneva:WHO;1997.

[19]. Anderson P, Hector MP, Rampersad MA. Critical $\mathrm{pH}$ in resting and stimulated whole saliva in groups of children and adults. Int J Paediatr Dent. 2001 Jul;11(4):266-73. Pubmed PMID: 11570442.

[20]. Dezan CC, Nicolau J, Souza DN, Walter LR. Flow rate, amylase activity, and protein and sialic acid concentrations of saliva from children aged 18,30 and 42 months attending a baby clinic. Arch Oral Biol. 2002 Jun;47(6):4237. Pubmed PMID: 12102757.

[21]. Soderling E. Practical aspects of salivary analyses" chapter 1: in "Human Saliva: Clinical Chemistry and Microbiology". Tenovuo JO, Vol. 1.

[22]. Wu KP, Ke JY, Chung CY, Chen CL, Hwang TL, Chou MY, et al. Relationship between unstimulated salivary flow rate and saliva composition of healthy children in Taiwan. Chang Gung Med J. 2008 May-Jun;31(3):281-6. Pubmed PMID: 18782951

[23]. Elizarova VM, Petrovich IuA. Ionizirovanny kal'tsi囚 v sliune $\operatorname{dete} \bigotimes$ pri mnozhestvennom kariese [Ionized calcium in the saliva of children with multiple caries]. Stomatologiia (Mosk). 1997;76(4):6-8. Russian. Pubmed PMID: 9381500.

[24]. Grindler E, King JD. Calcium, apparent calcium absorption and calcium balance in young and elderly subjects: Influence of protein intake. Am J Clin Path. 1972;58:376

[25]. Nikiforuk G. Understanding dental caries. Etiology and mechanism. Basic clin. aspects.

[26]. Mandel ID. The functions of saliva. Journal of dental research. 1987 Feb;66(1_suppl):623-7.

[27]. Edgar WM, Bowen WH, Cole MF. Development of rampant dental caries, and composition of plaque fluid and saliva in irradiated primates. J Oral Pathol. 1981 Aug;10(4):284-95. Pubmed PMID: 6798188.

[28]. Rankine CA, Moreno EC, Vogel GL, Margolis HC. Micro-analytical determination of $\mathrm{pH}$, calcium, and phosphate in plaque fluid. J Dent Res. 1985 Nov;64(11):1275-80. Pubmed PMID: 3867684.

[29]. Bagherian A, Asadikaram G. Comparison of some salivary characteristics between children with and without early childhood caries. Indian J Dent Res. 2012 Sep-Oct;23(5):628-32. Pubmed PMID: 23422609.

[30]. Jamal Abbas M, Khairi Al-Hadithi H, Abdul-Kareem Mahmood M, Mueen Hussein H. Comparison of Some Salivary Characteristics in Iraqi Children with Early Childhood Caries (ECC) and Children without Early Childhood Caries. Clin Cosmet Investig Dent. 2020 Nov 17;12:541-550. Pubmed PMID: 33235513.

[31]. Shahrabi M, Nikfarjam J, Alikhani A, Akhoundi N, Ashtiani M, Seraj B. A comparison of salivary calcium, phosphate, and alkaline phosphatase in children with severe, moderate caries, and caries free in Tehran's kindergartens. J Indian Soc Pedod Prev Dent. 2008 Jun;26(2):74-7. Pubmed PMID: 18603733.

[32]. Vijayaprasad KE, Ravichandra KS, Vasa AA, Suzan S. Relation of salivary calcium, phosphorus and alkaline phosphatase with the incidence of dental caries in children. J Indian Soc Pedod Prev Dent. 2010 Jul-Sep;28(3):156-61. Pubmed PMID: 21157046.

[33]. Kargul B, Yarat A, Tanboga I. A study of some salivary elements with respect to sex, age and caries in children. Saudi Dent J. 1998;10(3):78-82.

[34]. Shaw L, Murray JJ, Burchell CK, Best JS. Calcium and phosphorus content of plaque and saliva in relation to dental caries. Caries Res. 1983;17(6):5438. Pubmed PMID: 6580080.

[35]. Kittner D, Beetke E, Kötzschke R. Der Phosphat- und Kalziumgehalt im Gesamtspeichel bei Probanden mit hoher und niedriger Kariesprävalenz [Contents of phosphate and calcium in whole-saliva of test persons with high and low caries prevalence]. Stomatol DDR. 1990 May;40(5):217-9. German. Pubmed PMID: 2270580.

[36]. Ashley FP, Wilson RF. The relationship between calcium andhuman saliva and dental plaque. Archs Oral Boil 1978;23:69-73.

[37]. Karshan M. Factors in saliva correlated with dental caries. Journal of Dental Research. 1939 Oct;18(5):395-407.

[38]. Ben-Aryeh H, Fisher M, Szargel R, Laufer D. Composition of whole unstimulated saliva of healthy children: changes with age. Arch Oral Biol. 1990;35(11):929-31. Pubmed PMID: 1704211.

[39]. Preethi BP, Reshma D, Anand P. Evaluation of flow rate, $\mathrm{pH}$, buffering capacity, calcium, total proteins and total antioxidant capacity levels of saliva in caries free and caries active children: an in vivo study. Indian Journal of Clinical Biochemistry. 2010 Oct 1;25(4):425-8.

[40]. Amaechi BT, Higham SM. In vitro remineralisation of eroded enamel lesions by saliva. J Dent. 2001 Jul;29(5):371-6. Pubmed PMID: 11472810. 